\title{
WELFARE REGIMES AND SOCIAL COHESION REGIMES: DO THEY EXPRESS THE SAME VALUES ${ }^{1} ?$
}

\section{ABSTRACT}

Welfare regime types are classified according to the role played by three main institutions, namely the market, the state and the family. They can be reinterpreted as systems of exchanges for providing resources based on the main principles of liberty, equality and solidarity. Depending on the different possible dialectical relations between these three principles, they lead to different social cohesion regimes.

This paper is the first attempt to empirically test this hypothesis at European level by elaborating a measure of social cohesion based on values and creating a typology of social cohesion regimes. In comparison to welfare regimes, it invites to go one step further by considering the articulation between the three main principles and proposes a more precise classification for countries. The results invite further research on the links between welfare and social cohesion regimes. The analysis is based on data from the 2008 European Values Study (EVS) in 43 countries using principal component analysis, multidimensional scaling and cluster analyses.

\footnotetext{
${ }^{1}$ We recognize the significant contribution to this article by our late colleague, Paul Dickes. Had it not been for his untimely death in May 2012, Paul would probably have been the first author.
} 
Keywords: social cohesion, welfare typology, values, multidimensional scaling, cluster analysis, EVS. 


\section{Introduction}

Social cohesion is the main topic addressed by each society as being the most fundamental value of all societies. The origin of the concept is to be found in Durkheim (1893), in his work "Division of Labour in Society", in which he closely linked social cohesion to social solidarity and to collective consciousness.

Since the 1990s, the question of social cohesion has encountered a revival. At the political level, it is usually addressed to deplore its dissolution, based on the accumulation of a wide variety of juxtaposed indicators (World Bank, OECD, European Council, and European Commission). At the academic level, it also exhibits a large diversity of definitions and measures (Maxwell 1996, Gough and Olofsson 1999, Friedkin 2004, Bruhn 2009, Wietzke 2015) but most of the authors agree on its multidimensional characteristics (Jenson 1998, Berger 1998, Kearns and Forrest 2000, Chan et al. 2006, Rajulton et al. 2007).

A more comprehensive definition is provided by Bernard (1999) who postulates that welfare state regimes are tools for achieving and maintaining social cohesion. He considers welfare state regimes as historical compromises around the main principles of liberty, equality and solidarity. These three values, originating with the Enlightenment, represent the fundaments of democracy; they are related to each other, form a totality and, at the same time, contradict each other. From this permanent legal and 
normative negotiation or "dialectic of democracy" emerge specific types of social cohesion.

Liberal welfare states give priority to the market and promote limited state intervention and family solidarity, while putting (economic) liberty first. Conservative/corporatist welfare states give priority to the family and occupational categories over both market and state intervention and promote solidarity (between groups based on professional or family ties). Finally, social-democratic welfare states give priority to the state in order to reduce the dependency of individuals on both market and family, thus favouring equality.

To what extent do current individual values still correspond to these historical compromises? Is it possible to distinguish welfare state regimes on the basis of individual support to these main principles? In other words, do we find a concordance between the underpinning values of welfare regimes and the current values of the population? To answer this question allows to know to what extent social cohesion regimes are congruent with the typology of the usual welfare states, and not only to formulate hypotheses on their development but also to anticipate national answers towards welfare policy and towards the development of a free market policy.

This paper aims 1) to elaborate a measure of social cohesion on the basis of values that can be applied in any democratic framework 2) to test it at European level by creating a typology of social cohesion regimes and 3) to address the adequacy of the welfare regime by comparing these two 
typologies and testing how far the underpinning values overlap. It is the first attempt to contribute to both debates on social cohesion and the welfare state by empirically testing a) the operationalisation of a democratic definition of social cohesion, and b) the link between social cohesion and welfare states.

This paper is structured as follows. The first part consists of a brief discussion of the typology of welfare state regimes in European countries and presents some theoretical considerations on values and how to measure them, with a specific focus to the underlying values of social cohesion. The second part presents a methodology for measuring values and its application to micro data. The third part presents the results in two sub-sections; firstly, an empirical validation based on EVS data and secondly, a typology of social cohesion which is compared to that of welfare state regimes developed using the Esping-Andersen perspective. In the final part, we conclude and discuss the results.

\section{Welfare states, values and social cohesion}

\subsection{The Esping-Andersen typology and its extension}

In his typology based on the role played by the market, state and family, Esping-Andersen identifies three main welfare state regime types in western societies: liberal, conservative/corporative and social democratic. This typology has been widely discussed ${ }^{2}$, particularly in relation to its possible

\footnotetext{
${ }^{2}$ See Arts and Gelissen (2002, 2010), Ferragina and Seeleib-Kaiser (2011) for a review of welfare typologies.
} 
broadening to include further types, the classification of Central European countries and finally its resilience in the contemporary world.

One of the issues it has raised concerns the presence of a fourth regime: the Latin/Mediterranean type. For some observers (Leibfried 1992; Petmesidou 1996; Ferrera $1996^{3}$ ), it is not possible to classify southern European countries as simply a variant of the conservative/corporative regime as proposed by Esping-Andersen, because of their underdeveloped state provision, strong familialism, extreme fragmentation of the social security system, large gaps in social protection and selective distribution of benefits through clientelism. According to St-Arnaud and Bernard (2003), the Mediterranean model is more familialist than the corporatist/conservative one; programmes with redistributive and social safety net goals are less generous; and market performance is limited by labour market rigidities.

A second important issue concerns the Central and Eastern European countries. The fall of communist regimes raised the issue of how to qualify these new welfare states, the relevance of the Esping-Andersen typology being at the core of discussion. Some commentators argued that this typology was appropriate for the classification of Central and Eastern European countries, claiming that the differences between these countries and the regimes included in the related typology were only temporary (Abrahamson 1999; Esping-Andersen 1996; Deacon 1993, 1992). Others

\footnotetext{
${ }^{3}$ For a summary of the controversy, see Maria Karamessini (2008).
} 
maintained this typology was clearly inadequate for classifying Central and Eastern European countries, as they would preserve some important particularities of their recent history over the long term (Aidukaite 2009). In opposition to this, Ferge (2008) argues that these countries do not constitute a bloc in terms of culture, as their welfare culture has deeper roots than the period of the totalitarian system.

A third significant issue is that of the ongoing congruence between the Esping-Andersen typology elaborated during the 'Golden Age of welfare state expansion' (Taylor-Gooby 2010: 37) and current welfare regimes. Analysing this temporal aspect, Danforth (2014) points out that EspingAndersen elaborated his typology using cross-sectional data from 1980. Using data from 1950 to 2000 in 5-year intervals for 18 advanced capitalist democracies, Danforth finds the "tripartite typology" to be valid only for the period 1975 to 1985 .

Finally, as several commentators have observed, globalisation and the financialisation of economics have severely shaken the welfare regime of many states. In Europe, this has been accentuated by the European Monetary Union and European Union, which have had a significant impact on national budgets and social policies. The Lisbon Strategy (2000-2010) and its related social agenda, proposed common political and economic measures to reach shared social objectives in which full employment is at the core of the system. Thus the welfare system of each country has evolved on a more shared basis in the direction of market principles (Taylor-Gooby 2010). 
2.2 The welfare state as a mediator of social cohesion

The two main models of welfare states, the Bismarckian and the Beveridgian models, have the same objective of social cohesion, or keeping social order, but are rooted in two different ideologies. The first one stems from the end of the nineteenth century, focused on risks (sickness, accidents, aging, and invalidity) and was based on work-insurance. During this period of industrial development, the political objective was to regulate the proletariat and to stop socialist movements by developing social laws as well as sharing the benefits of economic growth.

The Beveridgian model was developed in Britain following the so-called report on "Social Insurance and Allied Services" from Beveridge in 1942 which pleaded for a restructuration of the current system. The political objective was to call for national unity during and after World War II (Kerschen 1995). This model was mostly applied in Nordic and Southern European countries, focused on basic needs, and was based on assistance to all citizens. It is usually defined by unity, universality, and uniformity (Rothstein 2002).

Despite these different underlying ideologies, one of the main objectives of social security is to maintain social cohesion (Berghman and Verhalle 2002, Saint-Arnaud and Bernard 2003). Bernard considers this to be a permanently renegotiated balance between the three main, which are liberty, equality, and solidarity. As they are very basic values, they are 
considered to be universal values (Haller, 2002). These values have contradictory relations: too great a focus on liberty leads to polarisation and community dislocation; too great an accent on equality leads to totalitarianism and disengagement; too great an emphasis on solidarity leads to regimentation and domination. To achieve and maintain social cohesion, the state has to constantly find a balance between these three main elements.

Simultaneously, there is permanent interaction between values and institutions - i.e. between institutionalised values and the welfare state regime - which leads to a process of change that affects both. Values change with changing circumstances and also through generational replacement (Inglehart 1990). Welfare regimes are the results of historical compromises, and "depending on the historical 'age' of a nation state and its size, huge differences exist" (Haller 2002:154). These considerations should guard us against any essentialist interpretation based on analysing values of social cohesion.

Next to values, Bernard proposes to take into consideration the concrete dimensions of social cohesion, that is, the manifestation of these three mobilising values in attitudes and behaviours. Ignoring the role of values, Saint-Arnaud and Bernard (2003) validate the typology of EspingAndersen, the identification of a Mediterranean welfare regime (Leibfried 1992, Ferrera 1996, Bonoli 1997) and the fact that European societies were still taking different paths to fostering social cohesion in the 1990s. Fenger (2007) extends this analysis to Central and Eastern European countries. He 
confirms the three welfare types (with no specific regime for Southern European countries), and identifies three further regimes, specific to the Eastern and Central European countries. The first, which he calls "postsoviet", includes Estonia, Latvia, Lithuania, Belarus, Russia and Ukraine. It is characterised by a lower level of social protection than in Northern and Western European countries, as well as higher inequalities and unemployment rates. The second groups together Hungary, Poland, the Czech Republic, Slovakia, Bulgaria and Croatia, and is similar to the postsoviet model, but has a higher level of social protection and a lower level of inequality. The last model characterises countries with the least developed welfare states, such as Georgia, Romania and Moldavia, and is called "indevelopment countries".

Bernard's theory of social cohesion (1999) has been partially validated by Dickes et al. (2010), who consider social cohesion as a multidimensional concept. They create a measure of attitudes and behaviours applied to the European Values Study of 1999, conducted in 33 European countries. However, the major role that Bernard assigned to values in defining social cohesion is not taken into account. A substantial contribution to this question is the work of Green and his collaborators (2009), who elaborate a typology of a social cohesion regime and propose a definition of social cohesion based on political and philosophical judgments. More specifically, taking into account different indicators linked to social situation, state interventionism, social and political participation and adhesion to values, they identify three social cohesion regimes that overlap 
the Esping-Andersen typology. In terms of values, they observe a strong adhesion to liberal and meritocratic values in liberal societies, with a weak valorisation of equality. Social-democratic societies, like liberal societies, adhere strongly to liberal values, but, unlike them, display a weak regard for meritocratic values. Curiously, and contrary to Bernard's expectations, equality is weakly valued in this kind of regime. This shift towards economic liberalism in Nordic countries is also observed by Chenu and Herpin (2006). Corporatist societies, named the "social market regime" by Green et al., pay the highest regard to equality. They also strongly adhere to meritocratic values and only weakly to liberal ones.

Unfortunately, Green et al. did not take into account the third dimension of Bernard's scheme, which is solidarity. Similarly, they did not include Central and Eastern European countries in their analyses. In this paper, therefore, we aim to measure adhesion to the values of liberty, equality and solidarity in the 47 European countries, using the European Values Study 2008, to identify social cohesion regimes on the basis of these three values, and to verify to what extent these regimes overlap with the typologies developed from the Esping-Andersen perspective. Thus, countries will be classified on the basis of the main principles currently supported by their residents and not according to geographical or historical criteria.

\section{Measures and methods}


Analyses are based on the European Values Study of 2008 (EVS). The data set is representative of the population aged 18 and over. For methodological reasons, we excluded four countries from our sample (Azerbaijan, Kosovo, Northern Ireland and Turkey). The original weighted pooled sample consisted of 43 countries and 61,796 individuals. To ensure equal weighting in the analyses the number of cases has been adjusted to 1,000 in each country.

Values are defined following the definition elaborated by Levy and Guttman (1985), which takes into account their multi-faceted nature. Following this definition and the presentation of the theoretical scheme of Bernard, we identify 11 items which are used to measure liberty, equality and solidarity in all countries. For each item, missing data varies between 2 and $11 \%$. Thus missing values were handled by Multiple Correspondence Analysis and imputed according to the application of Optimal scaling (Gifi, 1990). The polarity of scales was harmonised so that all scales indicate the same direction.

The five items selected for liberty are specifically related to the economic domain, as Bernard's theory argued. In this context, liberty has to be understood as the promotion of individual responsibility, competition and freedom of entrepreneurial activity. This leads to an opposition between those who are in favour of the free market and those who are more in favour of the intervention of the State in the economy (see table 1).

In Bernard's view, equality can be understood as equality of outcome or equality of opportunity. The first is a vision of social justice linked to the 
reduction of high income inequality between individuals. The second is a compromise between a guarantee of basic needs for all and the recognition of individual merits and efforts. In both cases, Bernard considers the state as an instrument for promoting equality. The EVS questionnaire does not contain common items for measuring equality of opportunity. Therefore, we selected two items linked to equality of outcome.

\section{TABLE 1.}

\section{[here]}

The four indicators illustrating solidarity are limited to family solidarity; they are related to filial love and the feelings of family responsibility and intergenerational support between parents and children. The first argument for this choice is an empirical one, as the EVS does not allow for the measurement of civil solidarity as it could be understood in Bernard's scheme. The second one is a theoretical one, as family solidarity is the key to distinguishing between the different types of social cohesion. EspingAndersen (1990) identifies family as one of the major pillars of welfare state regimes. In this respect, Masson (2009: 101) goes further, claiming that "family and intergenerational solidarity represent the conceptual divide between the three visions of welfare state". Other research evidenced that strong family ties imply more reliance on the family as an economic unit that provides goods and services and less on the market and on the state for social insurance (Alesina and Giuliano 2007). On the other side, we observe that the "modernisation" of social security, which involves a reduction of 
rights and the shorter duration of benefits, reallocates a main role to family support.

To test our theory, we used principal component analysis (PCA) to identify the structure of the selected items at individual level. We tested for internal consistency (Cronbach alpha coefficient) of the construct on all individuals.

Invariance of the theoretical constructs across countries was tested using multidimensional scaling (MDS) which enables the testing of facet theories (Canter 1985). This method "represents measurement of similarity (or dissimilarity) among pairs of objects as distances between points of a low-dimensional multidimensional space" (Borg and Groenen 2005: 3). The specific procedure of multidimensional scaling of individual differences (INDSCAL) or weighted MDS (Carrol and Chang 1970) includes group differences. It enables testing of the structural invariance of significance of the three values of social cohesion between countries, taking into account the structure common to all countries as well as each one of them (Kruskal and Wish 1978; Coxon 1982; Tournois and Dickes 1993).

In a final step, we conducted a hierarchical cluster analysis to develop our typology of social cohesion regimes. Similar population profiles are grouped according to the importance they attribute to values. This method "is the most appropriate [...] because it allows grouping countries that have similar characteristics across a set of variables, thus leading to homogeneous empirical types" (Saint-Arnaud and Bernard 2003).

\section{Results}


Conducting a PCA analysis with varimax rotation on the eleven items, we refer to Cattell's scree test (Cattell 1966) and identify three components which explain $46 \%$ of the total observed variance (Table 2). The three identified factors express the three values of social cohesion identified by Bernard in his theory.

TABLE 2.

[here]

\subsection{Empirical validation at European level}

The MDS PROXSCAL procedure was applied to the eleven items in the 43 countries. The outcomes suggest that a solution with two dimensions is sufficient to interpret the results. The common space is represented in figure 1 and shows a radex structure. Items belonging to the same component are grouped in three regions of the common space. The three regions correspond to the three components of the PCA.

Figure 1.4

[here]

Analysis of measurement equivalence was completed with a weighted MDS model which confirms that the common structure is similar in each of the 43 countries. This evaluation is done to complete the analysis by

\footnotetext{
${ }^{4}$ Stress and model fit diagnostics: Normalized Raw Stress: 0,029; Stress-I Kruskal: 0.171; dispersion: 0.971; Tucker's Coefficient of Congruence (correlation): 0.985.
} 
analysing the weight of each country within the common space. In figure 2, we observe one group of countries expressing their attraction towards the two dimensions of the common space.

Observing the mean stress of all items for each country, we see that it is much higher for ten countries, showing that the structure does not correspond to the one expected on the basis of theory alone. We examined MDS in detail for these ten countries, which are Armenia, Georgia, Romania, Latvia, Moldova, Portugal, Northern Cyprus, Hungary, Lithuania and Cyprus. For these countries, with the exception of Moldova, Hungary and Lithuania, the item "income should be more equal" (equal02) should be in one space with "equality is more important than liberty" (equal01) but it figures in the same space as economic liberty. The significance attributed to income scale (equal02) in these seven countries is quite different from the others. The item measuring social equality (equal01) seems to capture better the dimension of equality (Gundelach 2014).

Observing the mean stress by item for all countries, we see that it differs from one item to another. The item equal02 which is composed of a scale of income equality is not sufficiently adjusted to the common configuration. The mean stress of the item is equal to 0.061 while the total mean stress is equal to 0.029 . The item equal01 provides a better measure of equality. The items for the two other constructs (economic liberty and familial solidarity) are more reliable, and seem to receive a common interpretation in all countries. 
Figure 2.

[here]

Lastly, we tested cross-countries invariance measures by estimating internal consistency of the items with the Cronbach-alpha coefficient, which depends on mean correlations between items and on the number of items. It gives the lower limit of the fidelity of items collected to measure the construct and varies between 0 and 1 . The higher the value, the more consistent is the construct.

The internal consistency of the construct formed by the two items of equality is relatively weak, as the estimation is not consistent across most of the countries. We therefore measure equality with the single item equal01 for egalitarian value. The construct of economic liberty is measured by five items with a Cronbach alpha of 0.625 for the whole dataset, while the construct of familial solidarity is measured by four items with a Cronbach alpha of 0.602 for the whole dataset (Table 3). We have standardised the scores of these items and added them to create two composite indicators.

\section{TABLE 3.}

[here]

We succeeded in obtaining a reliable measure of economic liberty and familial solidarity. In comparison, the measure of equality may be 
considered as weak, which confirms the statement by Green et al. (2009) that EVS has a poor measure of equality.

4.2 A typology of social cohesion regimes

To identify a typology of social cohesion regimes based on the three values, we proceeded with a hierarchical analysis classification using Ward's minimum variance method, which minimises variance in clusters and maximises their homogeneity. With reference to the hierarchical tree, we kept a solution with 6 clusters. All correlations between variables and groups were highly significant (Fisher-Snedecor's F), and the explained variance is between $70 \%$ and $81 \%$. The coefficient Eta ${ }^{2}$ estimates the importance or consistency of classification and allows us to choose the solution with the lowest number of groups and a good internal validity (equality: $F(5,37)=32,7, p<.001, \eta^{2}=0.815$; economic liberty: $F(5,37)=17,7, p<.001$, $\eta^{2}=0.706$; familial solidarity: $\left.F(5,37)=30,4, p<.001, \eta^{2}=0.804\right)$.

We used standardised profiles mean scores to compare the values scores by country groups (Appendix 1). The characterisation of social cohesion was taken into account using the following rules: if the absolute value of the mean $z$ score is lower than or equal to 0.5 , the value is considered as determining the cluster at a low level and is taken into account for the interpretation. The next thresholds are $|0.5|<z \leq|1|$ for a high level; $|1|<z<|2|$ for a very high level, and $|2|<z$ for an extremely high level of determination. 
Based on the values of equality, economic liberty and familial solidarity, we identified six social cohesion regimes (Table 4).

Group 1. Familial, liberal and non-egalitarian: group 1 shows high scores for economic liberty and familial solidarity and a low score for equality. It consists of eight countries; most are in Eastern Europe and half are EU members. There are three post-communist countries (Bulgaria, Slovenia and Slovakia), two countries in development (Romania and Georgia), one post-soviet country (Belarus), one liberal country (Malta) and one country from the western Balkans (Albania).

Group 2. Non liberal: this group shows a depreciation of economic liberty (low score) and no significant scores for equality and familial solidarity. It is the largest group, with fourteen countries all located in Southern or Eastern Europe, and six of which are EU members. There are five post-soviet countries (Armenia, Estonia, Latvia, Russia, and Ukraine), four out of six southern welfare regimes (Cyprus, Northern Cyprus, Spain, and Greece), three out of seven post-communist countries (Croatia, Hungary, and Poland), one country in development (Moldova), and one country from the western Balkans (Serbia).

\section{TABLE 4.}

[here]

Group 3. Liberal non familial: group 3 shows low scores for equality, high scores for economic liberty and very low scores for familial solidarity. It 
consists of nine EU countries with the exception of Norway. It groups four out of five Scandinavian countries (Denmark, Finland, Norway, and Sweden), two out of four liberal welfare regimes (Great Britain, Ireland), two out of seven corporatist welfare regimes (Austria, The Netherlands) and one post-soviet country (Lithuania).

Group 4. Familial: this group shows a very strong depreciation of equality as well as economic liberty and a high appreciation for familial solidarity. It is the smallest group, composed of three countries all belonging to the former Yugoslavia (Bosnia-Herzegovina, Montenegro, Macedonia) and all candidates or potential candidates to European membership.

Group 5. Egalitarian familial: group 5 shows a very high valorisation of equality, a high valorisation of familial solidarity and no significant score for economic liberty. It is composed of four EU countries, two are corporatist welfare regimes (Belgium, France) and two are Mediterranean regimes (Italy and Portugal).

Group 6. Egalitarian, liberal and non-familial: this group expresses a very high valorisation of equality, a high valorisation of economic liberty, and a low score for familial solidarity. It consists of five countries. Three are corporatist welfare regimes (Germany, Luxembourg, and Switzerland), one is a social democratic regime (Iceland) and one is a post-communist country (Czech Republic).

This social cohesion regimes typology distinguishes European countries on an East-West axis and, to a certain extent, a North-South axis. However, it remains difficult to identify the welfare regimes proposed by 
Bernard (1999). With reference to welfare regimes typologies, we observe that two liberal countries (Great Britain and Ireland) and four socialdemocrat countries (Denmark, Finland, Norway, and Sweden) are included in the same liberal non-family cluster (3). On the other hand, corporatist countries are split between three models, the liberal, non-familial (3) (Austria and The Netherlands), the egalitarian, familial (5) (Belgium and France) and the egalitarian, liberal, and non-familial model (6) (Germany, Luxembourg, Switzerland). Countries belonging to Mediterranean welfare regimes are split between the non-liberal model (2) (Cyprus, Northern Cyprus, Spain and Greece) and the egalitarian, familial model (5) (Italy and Portugal).

Eastern and Central European countries fall into different groups. It is not really possible to identify post-communist, post-soviet regimes and indevelopment regimes as described by Fenger (2007). On the one hand, we observe that the countries of former Yugoslavia fall into three different groups: Albania and Slovenia belong to the group of familial, liberal and nonegalitarian countries (1), Croatia and Serbia belong to the group of nonliberal countries (2), while Bosnia-Herzegovina, Montenegro, and Macedonia form the group of familial countries (4). On the other hand, there is no empirical evidence for strong egalitarianism: all ECE countries belong to groups which are neutral towards equality or to groups which express a low or very low valorisation of equality, with the exception of the Czech Republic. In fact, we observe that the Slovak Republic belongs to the familial, liberal and non-egalitarian group (1) whereas the Czech Republic belongs to the egalitarian, liberal and non-familial one (6) (as mentioned by 
Kitschelt (2003), the Czech Republic displayed a rapid process of economic reforms towards liberalisation). Some authors state that the classification in Eastern and Central Europe is far too simple and does not express the diversity of the post-communist regimes when taking into account contextual elements (Ekiert and Hanson 2003; Kitschelt 2003). Our results are in line with this statement and require further research to identify causal mechanisms, which is beyond the scope of this work. The fact that EastCentral European (ECE) countries express basic values which are very different from each other confirms that they shaped their welfare culture before the "socialist dictatorship" (Ferge 2008; Inglot 2009). In a recent past, since the 1990s, they have also experienced different mechanisms of institutional change (Cerami 2009; Cook 2010). As changes are still going on, the current classifications of ECE countries can only be considered as temporarily valid.

\section{Conclusions and discussion}

We succeeded in measuring the values of liberty, equality, and solidarity which are the foundations of social cohesion as expressed in Bernard's theory. Following the facet approach of Levy and Guttmann (1985) we identified appropriate items in the questionnaire EVS 2008 for 43 countries. Using the PCA method we identified three components and tested for construct validity with MDS. At a final stage, we proceeded with a hierarchical analysis classification to create a typology of social cohesion 
regimes. We obtained six groups of countries which differ largely from each other, expressing different combinations of the perceptions of economic liberty, equality, and familial solidarity. Our typology fulfils the criteria of validity as described by Van Kersbergen (2013: 142): it is exhaustive and mutually exclusive. It identifies patterns and allows the classification of states with respect to their current ideology. It is a powerful tool for comparing current principles with the original basic values of the welfare states.

By identifying social cohesion regimes based on support for universal values, we contribute to two main debates. We validate the central intuition of Bernard, that the three universal values are simultaneously necessary and at the same time in opposition as three types of interrelations.

This is a first step in the contribution to identifying the relationship between social cohesion regimes and welfare regimes. From a policy perspective, taking such national ideational features into account would help policy choice. If we consider, for example, that Greece belongs to the group of countries that is characterised by only one feature, namely the negative support for economic liberty, then this result contributes to explaining the large public mobilisation again the austerity plans that the country has faced in the last years. Too large a gap between democratic values supported at the individual level and values that are conveyed at national or supranational levels by institutions such as the state, or supranational organisations such as the market, appear to threaten social cohesion. 
We have shown that universal values may be used to identify different ideologies and that these ideologies allow to create different clusters of countries. We discovered that the configurations of universal values allows for the grouping of countries with different recent histories or countries usually grouped in different clusters when considering macroeconomic indicators (GDP, social expenditures, rate of un/employment...). This grouping may appear as "counterintuitive" as it differs from those based on the usual macro-level indicators. It reveals, in fact, that nations may share common patterns of universal values even if they have experienced divergent paths towards economic development and a different political history.

Some countries share a common type of social cohesion, or a common architecture as regards the relations between values, but their respective welfare regimes are classified according to different types. Denmark and Great Britain share the same cluster of social cohesion regimes when they are categorised as social democratic and liberal welfare states. The value of economic freedom as well as individual responsibility is highly supported but then there is no agreement on how to reach this ideal or how to translate this objective into concrete steps. This social cohesion typology overlaps neither with those of welfare regimes developed on the basis of Esping-Andersen's one (1990) nor with previous groupings of social cohesion regimes (Green et al. 2009). This specific classification of countries shows new evidences, raises questions, from which in turn a number of hypothesis emerge. 
This pleads in favour of a further step, namely taking into consideration attitudes and behaviours simultaneously with values when measuring social cohesion. Citing Thurow (1996: 158-9), Bernard points out that the values of democracy or capitalism do not represent a unifying ideology. It is therefore necessary to consider the concrete dimensions of social cohesion and these are manifested when mobilising not just values but attitudes and behaviours simultaneously with values.

Secondly, Bernard considers equality as "a key dimension of social democratic order" (1999: 57), and argues that equality is linked to liberty and solidarity in a dialectical relationship. In this sense, social cohesion is intimately connected to the principle of social justice. Unfortunately, the use of EVS 2008 offers a restricted possibility for measuring equality. Our analysis measured unconditional equality with one single item and it is generally admitted that the use of one single item to identify a theoretical concept should be interpreted with caution, as it can lead to different conclusions, as observed by Han et al. (2012: 45) when comparing the results obtained by Arts and Gelissen (2001) and Green et al. (2009) in measuring meritocratic beliefs. This speaks in favour of developing the measurement of equality by introducing further questions related to this topic in the questionnaires prepared for the next waves of EVS.

On the other hand, the attempt to measure the principle of equality faces some difficulties linked to the interaction between values and institutions. Green et al. suggest that countries in which institutions show a high valorisation of any value appear to take it for granted and therefore fail 
to mention it in their preferences. This could explain why Nordic countries show a low support for equality.

This argument is not complete without the observation of the existence of a comprehensive shift to greater liberalism and the preeminence given to liberal rules. This again may be part of the explanation for the high valorisation we observe for the dimension of liberty, even in Nordic countries. Another hypothesis would be that individuals express support for the original principle that underpin welfare states. As the UK and Nordic countries have developed their welfare state on the Beveridgean model, we find support for the dimension of economic liberty and individual responsibility. From a theoretical point of view, it is also interesting to observe that support for economic liberty does not exclude support for equality (group 6). This calls for further research on the link between these two main dimensions.

Following the work by Danforth and our results, we may conclude that there is no empirical evidence that the welfare typology is still congruent with current social policy. Finally, with exception of the Czech Republic, we observe that most of the post-communist and post-soviet countries share the common feature of anti-liberal values, even if they belong to two different clusters.

Beckfield (2013) asked, when he observed a welfare 'retrenchment: a general reduction in the generosity of popular welfare programs' and a 'welfare convergence' in the context of European integration: 'the diminution 
of differences among welfare states' (p. 98), whether this meant "the End of equality in Europe?". This development currently does not receive support from most of the Eastern and Central European countries, something which clearly reveals negative support for the principle of economic liberty but at the same time very different levels of support for the principle of equality. How will this evolve?

From a wider perspective, some authors also claim that European social models are converging under the pressure of economic European integration (Beckfield 2013). On the contrary, some others think that specific differences will still be marked as welfare states remain nation-states: "These nation-states will still successfully claim the allegiance of most citizens and can make them go to war, pay taxes and social security contributions, and obey laws" (Arts 2002: 32). Furthermore, the same reasons behind social order that motivated its founders are still applicable. The question is that of the development of the balance between the three main principles, and particularly the level of acceptance of inequality under the influence of European social policy.

Acknowledgements

The authors would like to thank the anonymous reviewers for critical and constructive comments.

\section{References}

Abrahamson, P. (1999) 'The Welfare modelling Business', Social Policy and Administration 33(4): 394-415. 
Aidukaite, J. (2009) 'Poverty, urbanity and social policy in Central and Eastern Europe', in J. Aidukaite (ed.) Poverty, urbanity and social policy: Central and Eastern Europe compared, chap. 1, pp. 1-30, New-York: Nova Sciences Publishers, Inc.

Alesina A. and Giuliano P. (2007) 'The Power of the family', NBER Working paper $13051,54 \mathrm{p}$.

Arts, W. and Gelissen, J. (2001) 'Welfare states, solidarity and justice principles: Does the type really matter', Acta sociologica, 2001, vol. 44, 283299.

Arts, W. and Gelissen, J. (2002) 'Three worlds of welfare capitalism or more? A state of the art report', Journal of European Social Policy 12: 137158.

Arts, W. and Gelissen, J. (2010) 'Models of welfare state', in Castles, F., Leibfried, S., Lewis, J., Obinger H., Pierson, C. (eds) The Oxford Handbook of the welfare state, Oxford: Oxford University Press, chap. 39, pp. 569-583.

Beckfield, J. (2013) The End of equality in Europe? Current History, March:112(752):94-99.

Berger, P. (1998) The limits of social cohesion. Conflicts and mediation in pluralist societies. A report of the Bertelsmann foundation to the Club of Rome, Boulder, Colo: Westview Press.

Bernard, P. (1999) 'La cohésion sociale : critique d'un quasi-concept', Lien social et Politiques - RIAC 41: 47-59. 
Bonoli, G. (1997) 'Classifying Welfare state: a two dimensional approach', Journal of Social Policy 26(3): 351-372.

Borg, I. and Groenen, P.J.E. (2005) Modern Multidimensional Scaling. Theory and applications, New-York: Springer (2nd edition).

Bruhn, J. G. (2009) 'The Concept of social cohesion', in J. G. Bruhn, (eds) The Group Effect, Social cohesion and health outcomes, Springer US, New York, Chap. 2, pp. 31-48.

Canter, D. (1985) Facet theory: Approach to social research, New-York: Springer Verlag.

Cattell, R., B. (1966) Handbook of Multivariate Experimental Psychology, Chicago: Rand McNally.

Cerami, A. (2009) Mechanisms of Institutional Change in Central and Eastern European Welfare State Restructuring. In Cerami, A. and Vanhuysse, P. (eds), Post-Communist Welfare Pathways. Theorizing Social Policy Transformations in Central and Eastern Europe, Palgrave Macmillan: Basingstoke, pp. 35-52.

Chan J., Ho-Pong, T., Chan E. (2006) Reconsidering social cohesions: developing a definition and analytical framework for empirical research, Social Indicators Research, 75: 273-302.

Chenu, A. and Herpin, N. (2006) 'Le Libéralisme économique gagne les pays Nordiques, la France résiste', in H. Lagrange (dir.) L'Epreuve des inégalités, Paris, PUF, pp. 41-66. 
Cook, L. (2010) 'Eastern Europe and Russia' in F. Castles, Leibfried S., Lewis J., H. Obinger, C. Pierson (eds) The Oxford Handbook of the welfare state, Oxford: Oxford University Press, chap. 46, pp. 671-686

Coxon, A.P.M. (1982) The User's guide to multidimensional scaling. London: Heinemann.

Danforth, B. (2014) 'Worlds of welfare in time: A historical reassessment of the three-world typology', Journal of European Social Policy 24(2): 164-182.

Deacon, B. (1992) 'East European welfare: past, present and future in comparative context', in B. Deacon (ed.), The New Eastern Europe. Social Policy: Past, Present and Future, London: Sage Publications, pp. 1-31.

Deacon, B. (1993) 'Development in East European social policy', in C. Jones (ed.), New Perspectives on the Welfare State in Europe, London: Routledge, pp. 163-183.

Dickes, P., Valentova, M. and Borsenberger, M. (2010) 'Construct validation and application of a common measure of social cohesion in 33 European countries', Social Indicator Research 98(3): 451-473.

Ekiert G., Hanson S. E. (2003) 'Time, space and institutional change in Central and Eastern Europe', in Ekiert G., Hanson S. E. (eds) Capitalism and democracy in Central and Eastern Europe, Cambridge: Cambridge University Press, chap. 1, pp. 15-48.

Esping-Andersen, G. (1990) 'The Three Worlds of Welfare Capitalism' Cambridge: Polity Press \& Princeton: Princeton University Press. 
Esping-Andersen, G. (1996) 'After the Golden Age?', in G. Esping-Andersen (ed.), Welfare States in Transition. National Adaptations in Global Economies, London: Sage Publications, pp. 1-31.

Fenger, H. J. M. (2007) 'Welfare regimes in Central and Eastern Europe: incorporating post-communist countries in a welfare regime typology', Contemporary Issues and Ideas in Social Sciences 3(2):30 p.

Ferge, Z. (2008) 'Is there a specific East-Central European welfare culture?', in W. van Oorschot, M. Opielka and B. Pfau-Effinger (eds), Culture and welfare state: values, social policy in comparative perspective, London: Edward Edgar, pp. 141-161.

Ferragina, E. and Seeleib-Kaiser, M. (2011) 'Welfare regime debate: past, present, futures?', Policy and Politics, vol. 39, n4, pp. 583-611.

Ferrera, M. (1996) The Southern model of Welfare in Europe, Journal of European Social Policy, vol. 6, n¹, pp. 17-37

Friedkin N. E. (2004) Social cohesion, Annual Review of Sociology, vol. 30, pp. $409-425$

Gifi, A. (1990) Nonlinear multivariate analysis, New-York: John Wiley \& Sons.

Gough I., Olfsson G. (1999) ed. Capitalism and social cohesion. Essays on exclusion and integration. Basingstoke: Palgrave Macmillan, 213 p. 
Green, A., Janmaat, G. and Han, C. (2009) Regimes of Social Cohesion. London: LLAKES Research paper 1.

Gundelach, P. (2014) ‘Freedom or equality', in W. Arts and L. Halman (eds), Value contrasts and consensus in present-Day Europe: Painting Europe's Moral Landscapes, Leiden: Brill. EVS 15, pp. 143-161.

Haller M. (2002) 'Theory and method in the comparative study of values. Critique and alternative to Inglehart', European Sociological Review, vol. 18, n², pp. 139-158

Han, C., Janmaat, J. G., Hoskins, B., Green, A. (2012) Perceptions of Inequalities: implications for social cohesion, London: LLAKES Research Paper 35.

Inglehart, R. (1990) Culture shift in advanced industrial society. Princeton: Princeton University Press.

Inglot, T. (2009) 'Czech Republic, Hungary, Poland and Slovakia: Adaptation and reform of the Post-Communist 'Emergency Welfare States". In A. Cerami and P. Vanhuysse (eds), Post-communist welfare pathways. Theorizing social policy transformations in Central and Eastern Europe, Basingstoke: Palgrave Macmillan, pp.73-95.

Jenson, J. (1998) Les contours de la cohésion sociale: l'état de la recherche au Canada, Ottawa: Etude des RCRPP, nF/03, $56 \mathrm{p}$.

Karamessini, M. (2008) 'Continuity and change in the southern European social model', International Labour Review 147(1), pp. 43-70. 
Kearns, A., \& Forrest, R. (2000). Social cohesion and multilevel urban governance. Urban Studies, 37(5-6), 995-1017.

Kerschen, N. (1995) L'influence du rapport Beveridge sur le plan français de sécurité sociale de 1945. Revue française de science politique, août 1995, Volume 45, №4, p. 570-595.

Kitschelt H. (2003) Accouting for Postcommunist regime diversity: what counts as a good cause?, in G. Ekiert, S.E. Hanson (eds) Capitalism and democracy in Central and Eastern Europe, Cambridge: Cambridge University Press, chap. 2, pp. 48-86.

Kruskal, J.B. and Wish, M. (1978) Multidimensional scaling, London: Sage publications.

Leibfried, S. (1992) 'Towards a European welfare state? On integrating poverty regimes into the European community', in Z. Ferge and J.E. Kolberg (eds), Social Policy in a changing Europe, Frankfurt am Main: Campus Verlag, pp. 245-280.

Levy, S. and Guttman, L. (1985) 'A faceted cross-cultural analysis of some core social values', in D. Canter (ed.) Facet theory: Approach to social research, New-York: Springer Verlag, pp. 205-221.

OECD (2011) Perspectives on Global Development 2012, Social Cohesion in a Shifting World, Paris: OECD Publishing, 260 p.

Masson, A. (2009) Des liens et des transferts entre générations, Paris: Éditions EHESS. 
Maxwell, J. (1996). Social dimensions of economic growth: Conferences commemoratives Eric John Hanson, vol. VIII, Hansen Memorial Lecture, 25 January, University of Alberta.

Petmesidou, M. (1996), Social Protection in Greece: A Brief Glimpse of a Welfare State. Social Policy \& Administration, 30: 324-347.

Rajulton, F., Ravanera, Z., Beaujot R. (2007) Measuring social cohesion: an experiment using the canadian national survey of giving, volunteering and participating, Social Indicators Research (2007) 80: 461-492.

Rothstein B. (2002) 'Future of the universal welfare state', in Stein K. Survival of the European Welfare state, London: Routledge, chap. 13: 217233.

Saint-Arnaud, S. and Bernard, P. (2003) 'Convergence ou résilience ? Une analyse de classification hiérarchique des régimes providentiels des pays avancés', Sociologie et Sociétés 35(1), pp. 65-93.

Taylor-Gooby, P. (2010) Open markets and welfare values. Welfare values, inequality and social change in the silver age of the welfare state, European Societies 6(1), pp. 29-48.

Thurow, L. (1996) The Future of capitalism: how today's economic forces shape tomorrow's world. New-York: Penguin Books.

Tournois, J. and Dickes, P. (1993) Pratique de l'échelonnement multidimensionnel : de l'observation à l'interprétation, Bruxelles: De BoekWesmaël. 
Van Kersbergen, K. (2013) 'What are welfare state typologies and how are they useful, if it all?', in B. Greve (eds.) The Routledge Handbook of the Welfare State, Abingdon: Routledge, Chap. 14, pp. 139-47.

Wietzke, F.-B. (2015) Pathways from Jobs to Social Cohesion, World Bank Res Obs February 1, 2015 30: 95-123. 
Appendix 1. Characteristics of the different groups based on values scores for 43 countries [TABLE 5]

[here] 